\title{
The Productivity Equation for Giant Thick Gas Reservoirs with Bottom Water
}

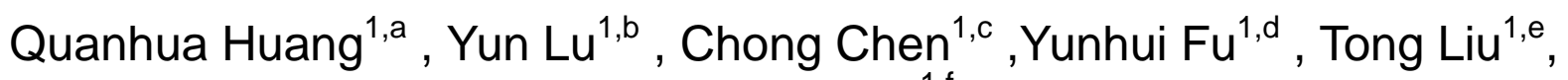 \\ Xinghua Deng ${ }^{1, f}$ \\ ${ }^{1}$ College of Petroleum Natual Gas Engineering, Southwest Petroleum University, \\ Chengdu Sichuan, 610500, China \\ aswpuhqh@126.com,,454637893@qq.com, '469185868@qq.com, d1161359753@qq.com, \\ e245002817@qq.com, ${ }^{\dagger} 544360790 @ q q . c o m$
}

Key words: Water drive gas reservoirs, non-Darcy flow, Radial flow, Hemispheric flow, Opening degree, Productivity equation

Abstract: For the production formulas of the gas reservoirs with bottom water, the models established in the past consider that only a small part of the gas layer is perforated and the entire region under the perforated zone is considered as the hemispheric flow, ignoring effects of the opening degree and formation anisotropy for gas production. The reality illustrates that the thick gas reservoirs may be larger opening degree and the flow hemispherical only exists near wellbore. The opening degree and the stratum anisotropy have great influence on production of gas well. Based on the previous models, this paper improves the models and deduces the productivity equation considering skin effect and the gas non-Darcy flow characteristics of the thick gas reservoirs with bottom water and analyzes the influence of the opening degree on the gas well productivity. The results of the examples show that the equations considering the skin effect, the non-Darcy flow and formation anisotropy are more realistic.

\section{Introduction}

Bottom water coning is an important factor to influence gas reservoir production rate [1-4]. As for the development of thick bottom-water reservoirs, to slow or even prevent the effect of bottom water coning, the producing wells usually partially penetrate the gas layer. Previous models [5-6] only took into account gas well opening degree is small (less than $1 / 3$ the thickness of the gas layer), and considered the bottom hole as a hemispherical flow across the region. However, for actual thick bottom-water reservoir, gas well may be big opening degree (above 1/2the thickness of the gas layer), so the entire area in the bottom can't be simply considered as a hemispherical flow. In perforated zone it is a planar radial flow and below perforated zone it is a combination of a hemispherical flow and a planar radial flow. And because of the effects of formation anisotropy, the permeability of hemispherical flow area can't be simply replaced with horizontal or vertical permeability. Meanwhile, in the process of real gas well productivity calculation, such as high gas rate well, fluid seepage velocity near wellbore area is too large to cause a high-speed non-Darcy flow, if not considering the non-Darcy effect, also lead to results mistake [7]. Based on percolation mechanism of the thick block bottom water gas reservoir, the author improved the formula derived by Zhang Qinghui [6] and deduced new gas well productivity equation considering the high-speed non-Darcy effect, skin pollution and formation anisotropy. 


\section{Model Establishment and Formula Derivation}

Supposing there is a huge thick bottom water block gas reservoir, whose gas layer thickness is $h$. Within the scope of the perforated interval $h_{P}$, gas flow is planar radial flow; within the scope of the $h-h_{P}$ under the bottom hole, the gas flow near wellbore area is hemispherical flow, and the gas flow far wellbore area is still planar radial flow. For such a kind of considering the actual situation of gas reservoir, the model is shown in fig. 1:

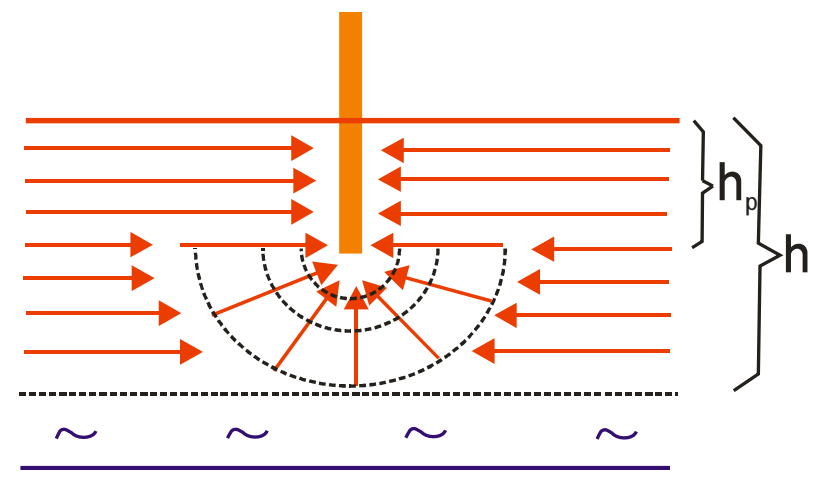

Fig. 1 Open degree imperfect well seepage flow diagram

\section{Productivity Equation of Open Gas Layer Segments}

Supposing the production of the gas reservoir upper portion is $q_{s c 1}$, the production formula [8] considering the bottom skin effect and the gas non-Darcy flow characteristics can be calculated by:

$$
p_{e}^{2}-p_{w f}^{2}=\frac{1.291 \times 10^{-3} q_{s c 1} T \bar{\mu} \bar{Z}}{K_{h} h_{p}}\left(\ln \frac{r_{e}}{r_{w}}+S+D_{1} q_{s c 1}\right)
$$

Where, $D_{1}$ in equation (1) is calculated by:

$$
D_{1}=2.191 \times 10^{-18} \frac{\beta \gamma_{g} K_{h}}{\bar{\mu} h_{p} r_{w}}
$$

Equation (1) can be rewritten as the binomial:

$$
p_{e}^{2}-p_{w f}^{2}=\frac{1.291 \times 10^{-3} T \bar{\mu} \bar{Z}}{K_{h} h_{p}} D_{1} q_{s c 1}^{2}+\frac{1.291 \times 10^{-3} T \bar{\mu} \bar{Z}}{K_{h} h_{p}}\left(\ln \frac{r_{e}}{r_{w}}+S\right) q_{s c 1}
$$

Where,

$$
\begin{aligned}
& A_{1}=\frac{1.291 \times 10^{-3} T \bar{\mu} \bar{Z}}{K_{h} h_{p}}\left(\ln \frac{r_{e}}{r_{w}}+S\right) \\
& B_{1}=\frac{1.291 \times 10^{-3} T \bar{\mu} \bar{Z}}{K_{h} h_{p}} D_{1}
\end{aligned}
$$

\section{Productivity Formula of Unopened Gas Layer}

Within the scope of the $h-h_{P}$ in near wellbore area, the flow of gas is half spherical flow. Due to the formation anisotropy, horizontal or vertical permeability cannot simply be regarded as the effective permeability of gas flow. The effective permeability of spherical flow $K_{s}$ [9] is calculated by: 


$$
K_{s}=\frac{3 K_{h} K_{v}}{\left(K_{h}+2 K_{v}\right)}
$$

Where, $K_{h}$ is the horizontal effective permeability, $K_{v}$ is the vertical effective permeability.

Without considering the bottom skin effect and non-Darcy flow, the production formula according to formula of hemispherical flow deduced by Chen Yuanqian [5] was:

$$
q_{s c 2}=\frac{Z_{s c} T_{s c} \pi K_{s}\left\lfloor\psi\left(p_{e}\right)-\psi\left(p_{w f}\right)\right\rfloor}{p_{s c} T\left(\frac{1}{r_{w}}-\frac{1}{r_{e}}\right)}
$$

Hemispherical productivity formula is represented by the pseudo-pressure in equation (7).

While using units of mines practical system and choosing $P_{s c}=0.101325 \mathrm{Mpa}, T_{s c}=293 \mathrm{~K}$ as standard condition the equation (7) can be transferred to:

$$
q_{s c 2}=\frac{774.6 K_{s}\left\lfloor\psi\left(p_{e}\right)-\psi\left(p_{w f}\right)\right\rfloor}{T\left(\frac{1}{r_{w}}-\frac{1}{r_{e}}\right)}
$$

In formulas (8), the gas layer is considered as a homogeneous zone, whose permeability from the outer boundary to the bottom hole stays the same. And in the actual cases, due to the "pollution" of drilling and stimulation to gas layer, the permeability near the bottom changes, namely the skin effect. Within the scope that the radius is from $r_{a}$ to $r_{w}$, considering the effect of skin factor $S$, formula (8) can be translated as:

$$
\psi\left(p_{e}\right)-\psi\left(p_{w f}\right)=\frac{1.291 \times 10^{-3} q_{s c 2} T}{K_{s}}\left[\frac{1}{r_{w}}-\frac{1}{r_{e}}\right]
$$

The drop of Pseudo-pressure $\Delta \psi_{\text {skin }}$ caused by the skin factor $S$ in the equation (8) can be calculated by:

$$
\begin{aligned}
\Delta \psi_{\text {skin }} & =\frac{1.291 \times 10^{-3} q_{s c} T}{K_{a}}\left(\frac{1}{r_{w}}-\frac{1}{r_{a}}\right)-\frac{1.291 \times 10^{-3} q_{s c} T}{K_{s}}\left(\frac{1}{r_{w}}-\frac{1}{r_{a}}\right) \\
& =\frac{1.291 \times 10^{-3} q_{s c} T}{K_{s} r_{w}}\left(1-\frac{r_{w}}{r_{a}}\right)\left(\frac{K_{s}}{K_{a}}-1\right)
\end{aligned}
$$

Combining equation (9) and equation (10), the total drop of Pseudo-pressure is calculated by:

$$
\psi\left(p_{e}\right)-\psi\left(p_{w f}\right)=\frac{1.291 \times 10^{-3} q_{s c 2} T}{K_{s} r_{w}}\left[1-\frac{r_{w}}{r_{e}}+\left(1-\frac{r_{w}}{r_{e}}\right)\left(\frac{K_{s}}{K_{a}}-1\right)\right]
$$

In the literature [10] and production formula of the spherical flow derived by Zhang qinghui [6], the spherical flow skin factor was defined as $\left(\frac{1}{r_{w}}-\frac{1}{r_{e}}\right)\left(\frac{K_{s}}{K_{a}}-1\right)$. Because the skin factor is a dimensionless quantity, so such a definition is clearly unreasonable. The author here makes the skin as $S=\left(1-\frac{r_{w}}{r_{e}}\right)\left(\frac{K_{s}}{K_{a}}-1\right)$, 
The formula (11) represented by pressure is calculate by:

$$
q_{s c 2}=\frac{774.6 K_{s} r_{w}\left(p_{e}^{2}-p_{w f}^{2}\right)}{T \bar{\mu} \bar{Z}\left(1-\frac{r_{w}}{r_{e}}+S\right)}
$$

The equation (7) can be transferred to

$$
p_{e}^{2}-p_{w f}^{2}=\frac{1.291 \times T \bar{\mu} \bar{Z}}{K_{s} r_{w}}\left(1-\frac{r_{w}}{r_{e}}+S\right) q_{s c 2}
$$

For the thick gas reservoir, gas production rate is generally large. Gas velocity flowing into the bottom hole is high, and the flow state of the gas is non-Darcy flow. There, the non-Darcy flow must be taken into account in the new model.

For thick gas reservoirs, generally, the gas production is larger, and the flow of high velocity gas in the bottom is the non-Darcy. Additional pressure drop caused by non-Darcy flow must be considered. Assuming $r_{e}>>h, r_{l}=h$ - $h_{\mathrm{P}}$, when $r_{w}<r<r_{1}$, the gas flow in the gas reservoir is the hemisphere flow and the non-Darcy seepage; When $r_{1}<r<r_{e}$, the gas flow in the gas reservoir is the plane radial flow and Darcy seepage.

Through relevant experiments, Forchheimer had put forward the following quadratic equation to describe the non-Darcy flow

$$
-\frac{d p}{d l}=\frac{\mu u}{K}+\beta \rho u^{2}
$$

For hemisphere flow, the equation (14) can be expressed to

$$
\frac{d p}{d r}=\frac{\mu u}{K_{s}}+\beta \rho u^{2}
$$

Where, $\quad \beta=\frac{7.644 \times 10^{10}}{k_{s}^{1.5}}$, the unit of $k_{s}$ is $10^{-3} \mu m^{2}$.

The second item on the right side of Formula (14) represent non-Darcy flow pressure drop, which is expressed by $P_{\mathrm{nD}}$ :

$$
d p_{n D}=\beta \rho u^{2} d r
$$

According to the following formula

$$
\begin{aligned}
& \rho=\frac{M_{\text {air }} \gamma_{g} p}{Z R T} \\
& u=\frac{q}{2 \pi r^{2}} \\
& q=\frac{p_{s c}}{T_{s c}} \frac{Z T}{p} q_{s c 2}
\end{aligned}
$$


Combining equation(17)、(18)、(19)and equation(16), and choosing $P_{s c}=0.101325 \mathrm{Mpa}, T_{s c}=293 \mathrm{~K}$ as the standard condition, it can be calculated by:

$$
\Delta p_{n D}^{2}=9.427 \times 10^{-22} \beta \lambda_{g} \bar{Z} T q_{s c 2}^{2}\left(\frac{1}{r_{w}^{3}}-\frac{1}{r_{1}^{3}}\right)
$$

Equation (20) can be transferred to:

$$
\Delta p_{n D}^{2}=1.291 \times 10^{-3} \frac{\bar{Z} \bar{\mu} T q_{s c 2}}{K_{s} r_{w}} D_{2} q_{s c 2}
$$

Where, $D_{2}$ is inertia or turbulence coefficient. In the formula derived by Zhang qinghui [6], $D_{2}$ is defined as

$$
D_{2}=5.456 \times 10^{-19} \frac{K \beta \gamma_{g}}{\bar{\mu}}\left(\frac{1}{r_{w}^{3}}-\frac{1}{r_{e}^{3}}\right)
$$

In the formula (22), the coefficient calculation is wrong, and the item $D_{2} q_{s c 2}$ is not dimensionless in the formula (21). Here, the author defines the correct inertia factor $\mathrm{D}_{2}$ as:

$$
D_{2}=7.302 \times 10^{-19} \frac{K_{s} \beta \gamma_{g}}{\bar{\mu}}\left(\frac{1}{r_{w}^{2}}-\frac{r_{w}}{r_{1}^{3}}\right)
$$

Incorporate additional pressure drop generated by non-Darcy flow in the formula (21) into the formula (13), it can be obtained:

$$
p_{1}^{2}-p_{w f}^{2}=1.291 \times 10^{-3} \frac{Z \bar{\mu} \bar{T} q_{s c 2}}{K_{s} r_{w}}\left(1-\frac{r_{w}}{r_{1}}+S+D_{2} q_{s c 2}\right)
$$

The formula (24) considering the non-Darcy flow of hemisphere is gas well productivity equation near wellbore. Where, $S$ reflects the impact of changes in the permeability near the bottom and $D_{2} q_{s c 2}$ reflects the changes of the bottom flow, namely high-speed non-Darcy flow effects.

Radial flow in far wellbore area:

$$
p_{e}^{2}-p_{1}^{2}=1.291 \times 10^{-3} \frac{q_{s c 2} T \bar{\mu} \bar{Z}}{K_{h} r_{1}} \ln \frac{r_{e}}{r_{1}}
$$

Combining equation (24) with equation (25), the gas capacity formula of unopened gas layer is calculated by

$$
\begin{aligned}
p_{e}^{2}-p_{w f}^{2}= & 1.291 \times 10^{-3} \frac{q_{s c 2} T \bar{\mu} \bar{Z}}{K_{s} r_{w}}\left(1-\frac{r_{w}}{r_{1}}+S+D_{2} q_{s c 2}\right) \\
& +1.291 \times 10^{-3} \frac{q_{s c 2} T \bar{\mu} \bar{Z}}{K_{h} r_{1}} \ln \frac{r_{e}}{r_{1}}
\end{aligned}
$$

Equation (26) can be rewritten as the binomial:

$$
\begin{aligned}
p_{e}^{2}-p_{w f}^{2}= & 1.291 \times 10^{-3} \frac{T \bar{\mu} \bar{Z}}{K_{s} r_{w}} D_{2} q_{s c 2}^{2} \\
& +1.291 \times 10^{-3} \bar{Z} \bar{\mu} T\left(\frac{1}{K_{s} r_{w}}\left(1-\frac{r_{w}}{r_{1}}+S\right)+\frac{1}{K_{h} r_{1}} \ln \frac{r_{e}}{r_{1}}\right) q_{s c 2}
\end{aligned}
$$


Where,

$$
\begin{aligned}
& A_{2}=1.291 \times 10^{-3} \bar{Z} \bar{\mu} T\left(\frac{1}{K_{s} r_{w}}\left(1-\frac{r_{w}}{r_{1}}+S\right)+\frac{1}{K_{h} r_{1}} \ln \frac{r_{e}}{r_{1}}\right) \\
& B_{2}=1.291 \times 10^{-3} \frac{T \bar{\mu} \bar{Z}}{K_{s} r_{w}} D_{2}
\end{aligned}
$$

According to the basic data of gas well and the properties of gas, the $A_{1}, A_{2}, B_{1}$ and $B_{2}$ can be calculated. Using the formula (3) and (27), $q_{s c 1}, q_{s c 2}$ can be calculated respectively. The total output $q_{s c}$ of gas well is calculated by

$$
q_{s c}=q_{s c 1}+q_{s c 2}
$$

When $q_{w f}=0$, the open flow potential of gas well can be calculated by the above equations.

\section{Example Analysis}

Taking five gas wells in a thick gas reservoir for instance, the AOF of gas wells can be calculate

\begin{tabular}{|c|c|c|c|c|c|c|}
\hline \multicolumn{2}{|r|}{ Well name } & N-1-1-DST1 & N-1-1-DST2 & N-1-2-DST1 & N-1-3-DST2 & N-1-4-DST1 \\
\hline \multicolumn{2}{|r|}{ layer } & $\mathrm{H} 3$ & $\mathrm{H} 4$ & H5 & H6 & $\mathrm{H} 7$ \\
\hline \multicolumn{2}{|c|}{ Horizontal permeability, $\mathrm{K}(\mathrm{mD})$} & 14.5 & 3.29 & 0.28 & 0.4 & 0.16 \\
\hline \multicolumn{2}{|c|}{ Vertical permeability, K (mD) } & 1.71 & 0.33 & 0.0383 & 0.075 & 0.025 \\
\hline \multicolumn{2}{|c|}{ thickness of the reservoir, $\mathrm{h}(\mathrm{m})$} & 46.7 & 57.3 & 112.76 & 32 & 68 \\
\hline \multicolumn{2}{|c|}{ thickness of the perforated, $h_{p}(m)$} & 30 & 30 & 73 & 25.9 & 60 \\
\hline \multicolumn{2}{|c|}{ Wellbore radius,$r_{\mathrm{w}}(\mathrm{m})$} & 0.1015 & 0.1015 & 0.1015 & 0.1015 & 0.1015 \\
\hline \multicolumn{2}{|c|}{ Temperature, $\mathrm{T}\left({ }^{\circ} \mathrm{C}\right)$} & 154 & 147 & 168 & 146.26 & 158 \\
\hline \multicolumn{2}{|c|}{ relative density of gas, $\gamma_{\mathrm{g}}$} & 0.584 & 0.584 & 0.584 & 0.584 & 0.584 \\
\hline \multicolumn{2}{|r|}{ Skin factor ,S } & 4 & 6.7 & 34.6 & 6.8 & -0.05 \\
\hline \multicolumn{2}{|c|}{ Supply radius, $\mathrm{r}_{\mathrm{e}}(\mathrm{m})$} & 500 & 500 & 500 & 500 & 500 \\
\hline \multicolumn{2}{|c|}{ original formation pressure, $\mathrm{P}_{\mathrm{i}}(\mathrm{MPa})$} & 36.947 & 36.84 & 53.7 & 36.02 & 45.12 \\
\hline \multicolumn{2}{|c|}{ Gas viscosity, $\mu_{\mathrm{g}}$ (mPa.s) } & 0.0236 & 0.0236 & 0.0276 & 0.0234 & 0.0257 \\
\hline \multicolumn{2}{|c|}{ Deviation coefficient, $\mathrm{Z}$} & 1.0768 & 1.0726 & 1.2214 & 1.0658 & 1.1451 \\
\hline \multirow{3}{*}{$\begin{array}{l}\text { Open-flow } \\
\text { capacity } \\
\left(10^{4} \mathrm{~m}^{3} / \mathrm{d}\right)\end{array}$} & Test data interpretation & 313.2 & 62.7 & 7.1 & 6.5 & 13.8 \\
\hline & $\begin{array}{l}\text { Not considering the } \\
\text { skin factor }\end{array}$ & 499.778 & 115.078 & 36.170 & 11.778 & 14.066 \\
\hline & Consider the skin factor & 339.671 & 64.280 & 7.127 & 6.525 & 14.173 \\
\hline
\end{tabular}
separately by above methods when considering skin factor or not. The results in table 1 as follow Table1 Open-flow capacity calculation of gas well

Table1 illustrates the results considering skin factor are similar to the results of testing data interpretation. Deviation of calculating results without taking into account of skin factor is bigger. Results showed that the skin factor has a great influence on gas well production capacity. Therefore, in the process of gas well production calculation, the influence of the bottom skin effect can't be ignored. 
Table2 The comparison between results of various methods

\begin{tabular}{ccccc}
\hline \multirow{2}{*}{ Well name } & \multicolumn{4}{c}{ Open-flow capacity $\left(10^{4} \mathrm{~m}^{3} / \mathrm{d}\right)$} \\
\cline { 2 - 5 } & Test data interpretation & Chen yuanqian method & Zhang qinhui method & Method presented in this paper \\
\hline N-1-1-DST1 & 313.200 & 14.328 & 4.687 & 339.671 \\
N-1-1-DST2 & 62.700 & 3.299 & 1.262 & 64.280 \\
N-1-2-DST1 & 7.100 & 0.427 & 0.091 & 7.127 \\
N-1-3-DST2 & 6.500 & 0.390 & 0.187 & 6.525 \\
N-1-4-DST1 & 13.800 & 0.202 & 0.141 & 14.173 \\
\hline
\end{tabular}

From table 2, for the great opening degree of the thick bottom-water gas reservoir, the previous models have not been applicable any more. The results compared to the actual situation have mistakes. The result calculated by the method presented in this paper is close to the actual result.

Taking N-1-1-DST2 Well for example, analyze the effect of open degree on gas well productivity. The results is shown in table 3 and fig. 2

Table 3 The influence of opening degree on production capacity

\begin{tabular}{ccc}
\hline $\begin{array}{c}\text { Opening degree } \\
(\%)\end{array}$ & $\begin{array}{c}\text { considering } \\
\text { the skin factor }\end{array}$ & $\begin{array}{c}\text { Not considering } \\
\text { skin factor }\end{array}$ \\
\hline 43.6 & 53.584 & 95.955 \\
52.4 & 64.280 & 115.078 \\
61.1 & 74.976 & 134.202 \\
69.8 & 85.672 & 153.327 \\
78.5 & 96.368 & 172.451 \\
87.3 & 107.064 & 191.575 \\
96.0 & 117.759 & 210.698 \\
\hline
\end{tabular}

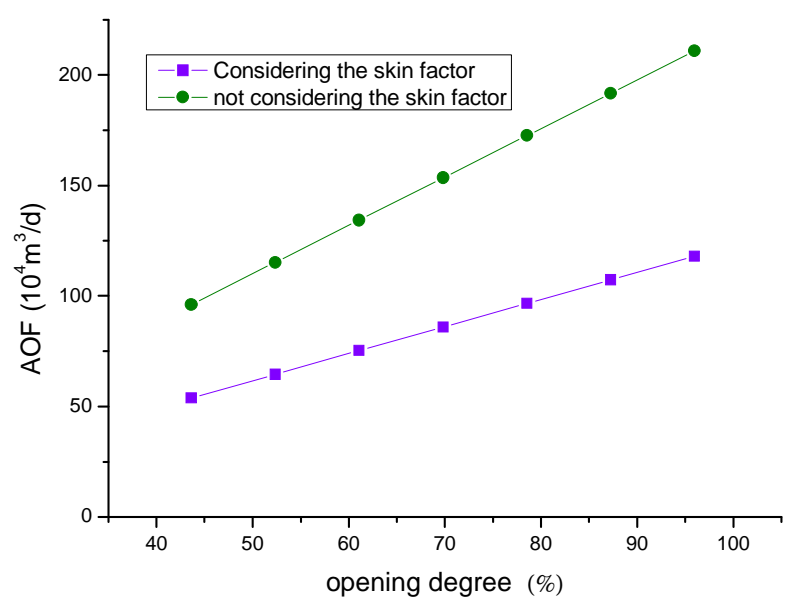

Fig.2 Relationship between Gas well open-flow capacity and open degree

From Fig. 2, AOF trends of gas well considering the skin effect or not are basically the same, all with the opening degree increases, AOF becomes large. 


\section{Conclusions}

1) For exploitation of thick bottom water gas reservoir, in order to slow down and avoid the influence of bottom water coning on gas well productivity, usually only the upper part of the gas layer is perforated. Because its opening degree is bigger than conventional bottom water gas reservoir, the flow state can't be regard as half spherical flow in total gas layer as usually, but in perforated zone it is a planar radial flow and below perforated zone it is a combination of a hemispherical flow and a planar radial flow.

2 ) Skin factor and non-Darcy flow of gas has great influence on the gas well production capacity, therefore, which need to be considered when calculating the gas well production capacity near the bottom of skin effect and gas non-Darcy flow. Opening degree has a great impact on gas well productivity. With the increase of open degree, gas well production capacity raises. Because of the problem of bottom water coning, it is very important to choose the appropriate opening degree of the bottom water gas reservoir.

\section{Explanation of symbols}

$p$ is pressure , $\mathrm{MPa} ; p_{e}$ is Formation pressure, $\mathrm{MPa} ; p_{w f}$ is Bottom hole flowing pressure, $\mathrm{MPa} ; \quad p_{1}$ is Radius $r_{1}$ pressure, $\mathrm{MPa} ; \bar{p}$ is Average pressure, $\mathrm{MPa} ; \Psi\left(p_{e}\right)$ - Pseudo-pressure under pressure of $p_{e}, \mathrm{MPa}^{2} /(\mathrm{mPa} . \mathrm{s}) ; \Psi\left(p_{w f}\right)$ - Pseudo-pressure under pressure of $p_{w f}$, $\mathrm{MPa}^{2} /(\mathrm{mPa} . \mathrm{s}) ; \mathrm{V}$ is volume of gas, $\mathrm{m}^{3} ; \mathrm{Z}$ is gas compressibility factor; $\mathrm{Z}_{\mathrm{sc}}$ is gas compressibility factor under standard condition; $\mathrm{n}$ is moles of gas; $\mathrm{R}$ is gas constant, $\mathrm{MPa} \cdot \mathrm{m}^{3} / \mathrm{kmol} . \mathrm{k}$; $\mathrm{m}$ is mass of gas, $\mathrm{t}$; $\mathrm{M}$ is molar mass of gas, $\mathrm{kg} / \mathrm{kmol}$; $\mathrm{T}$ is reservoir temperature, $\mathrm{K}$; $\mathrm{T}_{\mathrm{sc}}$ is temperature under standard condition, $K ; \rho$ is gas density under reservoir condition, $\mathrm{t} / \mathrm{m}^{3} ; \rho_{s c}$ is gas density under standard condition, $\mathrm{t} / \mathrm{m}^{3} ; \mathrm{q}_{\mathrm{sc}}$ is production under standard condition, $\mathrm{m}^{3} / \mathrm{d} ; \mathrm{q}$ is production under reservoir condition, $\mathrm{m}^{3} / \mathrm{d} ; \mathrm{A}$ is area of hemispherical flow, $\mathrm{m}^{2} ; \mathrm{r}$ is radius of hemispherical flow, $\mathrm{m}$; $\mathrm{r}_{\mathrm{e}}$ is supply radius, $\mathrm{m} ; \mathrm{r}_{\mathrm{w}}$ is Wellbore radius, $\mathrm{m} ; \mathrm{r}_{\mathrm{a}}$ is radius of formation polluted, $\mathrm{m} ; \mu_{g}$ is gas viscosity, mPa.s; $\mathrm{K}$ is effective permeability, $10^{-3} \mu \mathrm{m}^{2} ; \mathrm{K}_{\mathrm{h}}$ is horizontal effective permeability, $10^{-3} \mu m^{2} ; K_{v}$ is vertical effective permeability, $10^{-3} \mu m^{2} ; K_{s}$ is Spherical flow effective permeability, $10^{-3} \mu \mathrm{m}^{2} ; \mathrm{K}_{\mathrm{a}}$ is effective permeability of gas after pollution, $10^{-3} \mu \mathrm{m}^{2} ; \mathrm{S}$ is skin factor; $\beta$ is Speed coefficient, $\mathrm{m}^{-1} ; \mathrm{u}$ is velocity of gas phase, $\mathrm{m} / \mathrm{s} ; \gamma_{\mathrm{g}}$ is relative density of gas. 


\section{References}

[1]Song Zhaojie, Li Xiangfang, Li Zhiping,et al.A Model for Calculating Critical Production Rates of Water Coning with Consideration of Non-Darcy Flow[J].Acta Petrolei Sinica, 2012, 33(1): 106-111.

[2]Kabir C S. Predicting gas well performance coning water in bottom-water-drive reservoirs[C]//SPE Annual Technical Conference and Exhibition. Society of Petroleum Engineers, 1983.

[3]Mingxuan Y G L J J, Dehua L. Production Mechanism and Development Tactics on Sandstone Reservoirs with Bottom Water [J]. Acta Petrolei Sinica, 1997, 2.

[4]Jin L, Wojtanowicz A K, Hughes R G. An Analytical Model for Water Coning Control Installation in Reservoir With Bottom water[J]. Journal of Canadian Petroleum Technology, 2010, 49(05): 65-70.

[5]Chen Yuanqian, Sunbing, Jiang Fengguang, et al.Derivation and Application of Semi-Spherical Flow Production Formula of gas well, 2009, 18(03):1-4, 75.

[6]Zhang Qinghui, Li Xiangfang, Yuan Haiju, et al.Deliverability equation derivation of semi-spherical flow gas wells considering non-Darcy flow[J].Reservoir Evaluation and Development,2011,1(05):24-28.

[7]Luo yinfu,Huang Bingguang, Yi ga,et al.Well Test Analysis of Gas Well Production at Constant Pressure Accounting for High Velocity Non-Darcy Flow[J].Jouunnal of Southwest Petroleum University(Science\&Technology Edition), 2008, 30(2): 91-93.

[8]Li Shilun.Natural gas engineering[M].Beijing:Petroleum Industry Press, 2010:88-89.

[9]Zhu Yadong. Well Test Analysis Method of Spherical Flow[J].Well Teseting, 1990 (3): 26-33.

[10]Wang Xiaodong, Zhang Qibin, Zou Yanhua.Skin Factor and Flow Pattern[J].Well Teseting, 2005, 14(2): 1-3. 